\title{
Depressive attribution style and stressor uncontrollability increase perceived pain intensity after electrical skin stimuli in healthy young men
}

\author{
Matthias J Müller MD
}

MJ Müller. Depressive attribution style and stressor uncontrollability increase perceived pain intensity after electrical skin stimuli in healthy young men. Pain Res Manag 2013;18(4):203-206.

BACKGROUND: Depressive and pain symptoms often occur concurrently in patients with psychiatric disorders or somatic diseases, but the contribution of pre-existing dysfunctional cognitive schemata to pain perception remains unclear.

OBJECTIVE: To investigate the relationship between depression-related attribution styles and perceived pain intensity (PPI) after controllable versus uncontrollable electrical skin stimulation in healthy male individuals. METHODS: Causal attributions for negative events were measured using the attribution style questionnaire (ASQ) on the dimensions internal versus external (INT), global versus specific (GLO) and stable versus unstable (STA) in 50 men ( 20 to 31 years of age). Additionally, symptoms of anxiety and depression (measured using the Depression Scale) as well as baseline helplessness were assessed. Participants were randomly assigned to receive self-administered (controllable) or experimenter-administered (uncontrollable) painful skin stimuli. PPI was assessed after stress exposure using a visual analogue scale ( 0 to 100). Relationships between PPI and depression-related cognitions were calculated using correlation and multiple regression analyses.

RESULTS: Correlation analyses revealed a moderate correlation between PPI and ASQ-INT scores $(r=0.46)$. Following uncontrollable stress exposure, significantly higher PPI ratings $(\mathrm{P}=0.001)$ and a higher correlation between PPI and ASQ-INT $(\mathrm{r}=0.70)$ were observed. Multiple regression analysis showed an independent influence of stressor controllability $(\beta=0.39 ; \mathrm{P}=0.003)$ and ASQ-INT $(\beta=0.36 ; \mathrm{P}=0.006)$ on PPI.

DISCUSSION: These findings highlight the interaction of specific depression-related cognitions and stress controllability on pain intensity perception. standing of the cognitive aspects of pain intensity perception and improve psychological pain therapies focusing on attributions and controllability.

Key Words: Attribution styles; Controllability; Pain intensity
CONCLUSIONS: The results of the present study may facilitate under-

\author{
L'attribution dépressive et l'incontrôlabilité des \\ éléments stressants accroissent l'intensité perçue de \\ la douleur après une stimulation électrique cutanée \\ chez des jeunes hommes en santé
}

\begin{abstract}
HISTORIQUE : Les symptômes de dépression et de douleur sont souvent concomitants chez les patients ayant des troubles psychiatriques et des maladies somatiques, mais on ne sait pas quel est l'apport d'un schéma cognitif dysfonctionnel préexistant sur la perception de la douleur.

OBJECTIF : Examiner le lien entre les types d'attribution dépressive et l'intensité perçue de la douleur (IPP) après des stimulations électriques cutanées contrôlables et incontrôlables chez des hommes en santé.

MÉTHODOLOGIE : Les chercheurs ont mesuré les attributions causales d'événements négatifs au moyen du questionnaire sur le type d'attribution (ASQ) portant sur les dimensions internes ou externes (INT), globales ou spécifiques (GLO) et stables ou instables (STA) chez 50 hommes (de 20 à 31 ans). Ils ont également évalué les symptômes d'anxiété et de dépression (selon l'échelle de dépression) et le sentiment d'impuissance au départ. Ils ont réparti les participants au hasard afin qu'ils reçoivent une stimulation cutanée douloureuse qu'ils s'administraient eux-mêmes (contrôlable) ou que leur administrait l'expérimentateur (incontrôlable). Ils ont évalué l'IPP après l'exposition au stress au moyen d'une échelle analogique visuelle $(0$ à 100$)$. Ils ont calculé la relation entre l'IPP et les facteurs cognitifs liés à la dépression au moyen d'analyses de corrélation et de régression multiple.
\end{abstract}

RÉSULTATS : Les analyses de corrélation ont révélé une relation modérée entre l'IPP et les indices de l'ASQ-INT $(r=0,46)$. Après une exposition au stress incontrôlable, les chercheurs ont observé un taux d'IPP considérablement plus élevé $(\mathrm{P}=0,001)$ et une corrélation plus élevée entre l'OPP et l'ASQ-INT $(\mathrm{r}=0,70)$. L'analyse de régression multiple a révélé une influence indépendante de la contrôlabilité du stress $(\beta=0,39 ; \mathrm{P}=0,003)$ et de l'ASQ-INT $(B=0,36 ; \mathrm{P}=0,006)$ sur l'IPP.

EXPOSÉ : Ces résultats font ressortir l'interaction des éléments cognitifs spécifiques liés à la douleur et la contrôlabilité du stress sur la perception d'intensité de la douleur.

CONCLUSIONS : Les résultats de la présente étude peuvent faciliter la compréhension des aspects cognitifs de la perception de l'intensité de la douleur et améliorer les thérapies psychologiques de la douleur axées sur les attributions et la contrôlabilité.

$\mathrm{M}_{\mathrm{n}}$ any patients with major depression report painful physical complaints (1). In addition, a large proportion of patients with chronic pain suffer from depression. Fibromyalgia is a disorder sharing common features of both depression and pain disorders $(2,3)$. Recent studies have shown that higher perceived pain intensities and negative pain-related cognitions were associated with depression in chronic pain patients (4) and with lower quality of life in patients with major depression and pain complaints (5). However, it remains unclear whether specific depression-related cognitive schemata and states predispose to intensified pain perception and the development of chronic pain, or whether acute and chronic pain may worsen or even cause depression. The great impact of persistent painful states and pain treatment on depressive symptoms and related cognitions has been demonstrated (6). Accordingly, situational dysfunctional cognitions have been linked to lower thresholds and higher intensity ratings after experimentally induced pain, whereas dispositional measurements have not (7). The predictive properties of cognitive schemata associated with depression as risk factors for the development of painful states have, thus, been questioned.

Basic research has revealed specific cognitive and emotionalaffective components of neurobiological pain processing (8-10), which likely contribute to the clinically relevant overlap between depressive and pain disorders. Specifically, uncontrollability and unpredictability of painful stressors have been demonstrated to be extremely important modifiers of pain perception (11-13). Unpleasantness and helplessness of potentially painful stimuli appear to be associated with increased

Vitos Clinics for Psychiatry, Psychosomatic Medicine, and Psychotherapy Giessen and Marburg; Academic Hospital, University of Giessen, Giessen, Germany

Correspondence: Dr Matthias J Müller, Clinic for Psychiatry and Psychotherapy Giessen, Licher Straße 106, D-35394 Giessen, Germany.

Telephone 49-641-403-229, fax 49-641-403-506, e-mail mjmueller@gmx.de 
TABLE 1

Sample characteristics $(n=50)$

\begin{tabular}{lcc}
\hline & Mean \pm SD & Range \\
\hline Age, years & $24.6 \pm 2.7$ & $20-31$ \\
Body mass index, $\mathrm{kg} / \mathrm{m}^{2}$ & $22.4 \pm 1.7$ & $18.6-27.4$ \\
Smoking status, $\mathrm{n}(\%)$ & $24(48)$ & \\
Depressive symptoms (DS) & $11.0 \pm 4.1$ & $0-18$ \\
Anxiety symptoms (MAS) & $8.1 \pm 4.8$ & $1-22$ \\
Perceived Pain Intensity (PPI) & $41.0 \pm 29.6$ & $0-92$ \\
Attribution Style Questionnaire & & \\
$\quad$ Total score & $88.5 \pm 14.2$ & $61-128$ \\
Internal versus external & $36.4 \pm 10.1$ & $13-53$ \\
Global versus specific & $26.2 \pm 7.8$ & $12-43$ \\
Stable versus variable & $25.9 \pm 8.7$ & $11-45$ \\
\hline
\end{tabular}

DS Depression Scale; MAS Manifest Anxiety Scale; PPI Perceived pain intensity after stress exposure (0 to 100)

pain intensity, whereas focusing attention on painful events appears to be related to a lowered pain perception threshold (14).

In this context, we studied the relationship between attribution styles and perceived pain intensity (PPI) after controllable or uncontrollable, experimentally induced, potentially painful skin stimuli in healthy young men. We hypothesized that depression-related cognitive schemata are associated with higher degrees of PPI, particularly after uncontrollable painful stimulus conditions.

\section{METHODS}

\section{Participants}

The present study was part of a larger project investigating the effects of uncontrollable stress on psychological and physiological parameters not reported here. Data from 50 healthy men (18 years of age and older) without a history of severe medical disease, psychiatric disorders and/or psychotherapy within the past two years, who were not taking psychotropic or pain medication and who had complete questionnaire data, were included in the present analysis (15). All experiments were performed at the Department of Psychology at the University of Giessen (Geissen, Germany), in accordance with the institutional review board and after all participants provided written informed consent. No formal approval letter was required.

\section{Study design and procedure}

Participants were randomly assigned to a harmless, potentially painful procedure under either controllable $(n=26)$ or uncontrollable conditions $(n=24)$. Electrical skin stimuli were generated by a transformer/ condensor device applied by two $\mathrm{Ag} / \mathrm{AgCl}$ electrodes fixed to the nondominant forearm using a conventional device $(15,16)$. A stimulus intensity (approximately $10 \mathrm{~mA}$ ) was used to ensure that all subjects received 'mildly painful' stimuli at comparable physical intensities (15). All participants were exposed to 30 stimuli with a mean interstimulus interval of approximately $20 \mathrm{~s}$ (10 min duration of stress exposure).

Under controllable conditions, stimuli were self-administered within an interval of $10 \mathrm{~s}$ at the individual's choice by pressing a button on a desk in front of them. At the start of a single trial, a green light-emitting diode (LED) in front of the participants was activated. If the button was not pressed, the stimulus was automatically applied after $10 \mathrm{~s}$. In both cases the green LED changed to a red LED and the stimulus generator was blocked to avoid more than one stimulus within one trial. A new trial was indicated again by a change of LED activation (from red to green) after the end of the $20 \mathrm{~s}$ interval. Under uncontrollable conditions, stimuli were applied by the experimenter according to a random schedule within the $10 \mathrm{~s}$ intervals; all other features of the experiment were identical.

\section{Assessments}

Sociodemographic data, depression-related attribution styles and psychological variables were assessed before the experiment. Anxiety
TABLE 2

Correlations with perceived pain intensity

\begin{tabular}{|c|c|c|c|}
\hline \multirow[b]{2}{*}{ Characteristic } & \multirow{2}{*}{$\begin{array}{l}\text { Total } \\
\text { group } \\
(n=50)\end{array}$} & \multicolumn{2}{|c|}{ Condition } \\
\hline & & $\begin{array}{c}\text { Controllable } \\
(n=26)\end{array}$ & $\begin{array}{l}\text { Uncontrollable } \\
\qquad(n=24)\end{array}$ \\
\hline Age, years & 0.12 & 0.31 & -0.34 \\
\hline Body mass index, $\mathrm{kg} / \mathrm{m}^{2}$ & -0.08 & -0.06 & 0.08 \\
\hline Smoking (yes/no) & -0.25 & -0.24 & -0.21 \\
\hline Depressive symptoms (DS) & 0.28 & 0.34 & 0.34 \\
\hline Anxiety symptoms (MAS) & 0.04 & 0.22 & 0.10 \\
\hline Subjective helplessness (SHL) & 0.21 & 0.37 & 0.05 \\
\hline \multicolumn{4}{|l|}{ Attribution Style Questionnaire } \\
\hline Total score & 0.26 & 0.15 & 0.33 \\
\hline Internal versus external & 0.46 & 0.09 & $0.70^{\star}$ \\
\hline Global versus specific & 0.13 & 0.17 & -0.03 \\
\hline Stable versus unstable & -0.23 & 0.01 & -0.31 \\
\hline
\end{tabular}

DS Depression Scale; MAS Manifest Anxiety Scale; SHL Subjective helplessness at baseline (item mean). *Significant difference of correlation coefficients between controllable and uncontrollable conditions $(P<0.01)$

was assessed using the Manifest Anxiety Scale (17), focusing mainly on autonomic anxiety symptoms in nonclinical samples (50 items, sum score range 0 to 50 ). Depressive symptoms were measured using the Depression Scale (18) using both parallel versions (D, D`) to enhance reliability (32 items, sum score range 0 to 96). Causal beliefs regarding the negative outcome of events were explored using a German version of the Attribution Style Questionnaire (ASQ) (19-21). The ASQ measures individual differences in three attribution dimensions (internality versus externality [INT], globality versus specificity [GLO] and stability versus instability [STA]). Ratings on globality, stability and internality (1 to 7) for the eight negative events were summed, resulting in total ASQ scores (ASQ-TOT, range 24 to 168) and scores for the three subscales (INT, GLO and STA, range seven to 56), with higher scores reflecting a higher risk for cognitions associated with depression and helplessness. PPI was judged on a $100 \mathrm{~mm}$ visual analogue scale.

\section{Statistical analyses}

Values are reported as mean \pm SD. Group differences were analyzed using unpaired $t$ tests, and relationships between parameters were evaluated using Pearson correlation coefficients and multiple regression analyses. A standard multiple regression analysis including potential predictors of PPI was computed, followed by a final regression model with the remaining significant predictors. All statistical analyses were performed using SPSS version 15.0 (IBM Corporation, USA). The level of statistical significance was set at $\alpha=0.05$.

\section{RESULTS}

Table 1 summarizes the sample characteristics, including sociodemographic data and depression-related psychological variables.

Comparison between the experimental conditions revealed a significantly higher PPI after uncontrollable stress exposure (controllable: PPI 27.7 \pm 26.3 , uncontrollable: PPI $55.5 \pm 26.3 ; t$ test $\mathrm{P}=0.001$ ). Mean scores of attribution styles, anxiety and depressive symptoms were comparable between both randomly assigned experimental groups ( $t$ tests, $\mathrm{P}>0.15)$.

Age, body mass index (BMI) and smoking status were not significantly associated with anxiety and depression levels. Anxiety scores (Manifest Anxiety Scale) showed a low correlation with ASQ-STA scores $(\mathrm{r}=0.30)$. ASQ total and subscale scores (INT, GLO, STA) were highly correlated $(r>0.50)$ while a correlation between ASQ subscale scores was absent $(r<0.2)$. Depressive symptoms (Depression Scale) were moderately correlated with ASQ total scores $(r=0.39)$, and ASQ-INT scores $(\mathrm{r}=0.42)$. Table 2 shows the correlations between PPI scores after stress exposure and psychological variables in the pooled sample and in both experimental groups separately. 
Low correlations were found between PPI and depressive symptoms $(\mathrm{r}=0.28)$ and moderate correlations between PPI and the internal-external ASQ subscale (ASQ-INT) $(r=0.46)$ in the total sample, whereas a high correlation between PPI and ASQ-INT emerged only in the group confronted with uncontrollable stress $(r=0.70)$. The difference of this correlation (PPI; ASQ-INT) between controllable and uncontrollable conditions was statistically significant $(\mathrm{P}=0.009)$.

Figure 1 illustrates the relationship between PPI and internal attributions of negative events under controllable and uncontrollable stress conditions.

An additional multiple regression analysis revealed independent significant contributions of an internal attribution style (ASQ-INT) $(\beta=0.29, P=0.049)$ and stressor controllability $(B=0.38, P=0.011)$ to predict the PPI. All other predictors were not statistically significant (age, BMI, smoking status, anxiety, depression score, ASQ-GLO and ASQ-STA; $P>0.10)$. The total model explained $R^{2}=43.0 \%$ of variance in PPI $(\mathrm{R}=0.66 ; \mathrm{P}=0.005)$. The final regression model including only the remaining significant predictors of PPI corroborated the initial regression model (ASQ-INT: $\beta=0.36, P=0.006$; stressor controllability: $\left.B=0.39, \mathrm{P}=0.003 ; \mathrm{R}^{2}=33.0 \%, \mathrm{R}=0.575, \mathrm{P}<0.0005\right)$. All other predictors were not statistically significant (age, BMI, smoking status, anxiety, depression score, ASQ-GLO and ASQ-STA); $\mathrm{P}>0.10$ ); the total model explained $\mathrm{R}^{2}=43.0 \%$ of variance in PPI $(\mathrm{R}=0.66 ; \mathrm{P}=0.005)$.

\section{DISCUSSION}

The present study revealed a specific interaction between having an internal locus of control for negative events and the PPI after uncontrollable painful laboratory stimuli in healthy young men. The internal/external dimension of causal attributions (ASQ) explained approximately $50 \%$ of the variance in pain intensity perception only after uncontrollable painful skin stimuli, whereas no correlation could be found after controllable painful stress despite identical physical properties. Only depressive symptoms (18) showed a low correlation with PPI ratings. Furthermore, depressive symptoms were moderately correlated with an internal attribution style for negative events, highlighting the validity of the present findings. Anxiety and the remaining dimensions of attribution style (ASQ total score, global and stable causal attributions of negative events) did not show substantial associations with the PPI.

\section{REFERENCES}

1. Lee P, Zhang M, Hong JP, et al. Frequency of painful physical symptoms with major depressive disorder in Asia: Relationship with disease severity and quality of life. J Clin Psychiatry 2009;70:83-91.

2. Fietta P, Manganelli P. Fibromyalgia and psychiatric disorders. Acta Biomed 2007;78:88-95.

3. Palomino RA, Nicassio PM, Greenberg MA, Medina EP Jr. Helplessness and loss as mediators between pain and depressive symptoms in fibromyalgia. Pain 2007;129:185-94.

4. Ho PT, Li CF, Ng YK, Tsui SL, Ng KF. Prevalence of and factors associated with psychiatric morbidity in chronic pain patients. J Psychosom Res 2011;70:541-547.

5. Chung KF, Tso KC, Yeung WF, Li WH. Quality of life in major depressive disorder: The role of pain and pain catastrophizing cognition. Compr Psychiatry 2012;53:387-95.

6. Fishbain DA, Cole B, Cutler RB, Lewis J, Rosomoff HL, Rosomoff RS. Chronic pain and the measurement of personality: Do states influence traits? Pain Med 2006;7:509-29.

7. Campbell CM, Kronfli T, Buenaver LF, et al. Situational versus dispositional measurement of catastrophizing: Associations with pain responses in multiple samples. J Pain 2010;11:443-53.

8. Frot M, Mauguière F, Magnin M, Garcia-Larrea L. Parallel processing of nociceptive A-delta inputs in SII and midcingulate cortex in humans. J Neurosci 2008;28:944-52.

9. Neugebauer V, Galhardo V, Maione S, Mackey SC. Forebrain pain mechanisms. Brain Res Rev 2009;60:226-42.

10. Peyron R, Laurent B, García-Larrea L. Functional imaging of brain responses to pain. A review and meta-analysis. Clin Neurophysiol 2000;30:263-88.

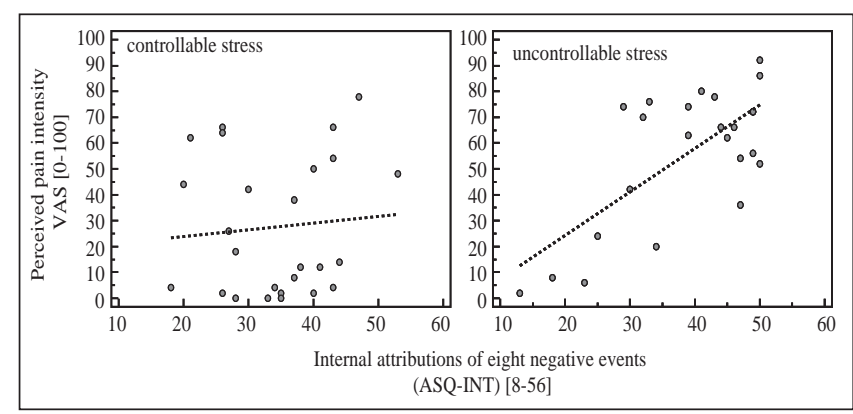

Figure 1) Correlations between perceived pain intensity and internal attribution style. ASQ-INT Attribution Style Questionnaire - internal versus external; VAS Visual analogue scale

In addition to self-report, the thorough screening procedure ensured that study participants had no current or past major somatic or psychiatric disorders. While most clinical studies recognize depression as a confounder of pain coping mechanisms (22), the present findings involving healthy young men could elucidate the interaction among genetically or developmentally acquired dispositions and situational factors. The specific importance of the internal/external dimension of causal attributions is consistent with previous reports in patients with depression or chronic pain $(23,24)$. Depression scores were related to this cognitive propensity to attribute negative outcomes to internal causes in our healthy sample. Learned helplessness theory suggests that uncontrollable aversive events can cause emotional, motivational and cognitive deficits (25-27).

Repeated uncontrollable painful stimuli can lead to states of helplessness, and amplified subjective pain intensity $(15,28)$. In addition, the present analysis shows that a specific interaction of habitual and situational factors related to control perception are crucial for the individual's pain intensity perception.

Personality traits and other psychological factors that were not assessed in the present study may also have a strong impact on pain processing and pain intensity perception (eg, catastrophizing) $(7,29)$ and may be linked to the more basic theory of control and helplessness (30). Significant limitations of the present experimental study were most notably the limited sample size and the selection of men (31). Therefore, additional studies are required to replicate the findings.

11. Christianson JP, Thompson BM, Watkins LR, Maier SF. Medial prefrontal cortical activation modulates the impact of controllable and uncontrollable stressor exposure on a social exploration test of anxiety in the rat. Stress 2009;12:445-50.

12. Strigo IA, Simmons AN, Matthews SC, Craig AD, Paulus MP. Association of major depressive disorder with altered functional brain response during anticipation and processing of heat pain. Arch Gen Psychiatry 2008;65:1275-84.

13. Thompson SC. Will it hurt less if I can control it? A complex answer to a simple question. Psychol Bull 1981;90:89-101.

14. Borckardt JJ, Reeves ST, Frohman H, et al. Fast left prefrontal rTMS acutely suppresses analgesic effects of perceived controllability on the emotional component of pain experience. Pain 2011;152:182-7.

15. Müller MJ. Helplessness and perceived pain intensity: Relations to cortisol concentrations after electrocutaneous stimulation in healthy young men. Biopsychosoc Med 2011;5:8.

16. Kimmel HD, King J, Hudy JJ, Gardner KA. A mutual inductance shocker. Behav Res Meth Instr 1980;12:605-6.

17. Taylor JA. A personality scale of manifest anxiety. J Abnorm Soc Psychol 1953;18:285-90.

18. Von Zerssen D. Depressivitäts-Skala. Göttingen: Beltz Test GmbH, 1975.

19. Brunstein JC. Attributionsstil und Depression; erste Befunde zur Reliabilität und Validität eines deutschsprachigen Attributionsstilfragebogens. Z Diff Diag Psychol 1986;7:45-53.

20. Peterson C, Semmel A, Metalsky G, Abramson LY, Baeyer C, Seligman MEP. The Attribution Style Questionnaire. Cogn Ther Res 1982;6:287-300. 
21. Poppe P, Stiensmeier-Pelster J, Pelster A. ASF-E Attributionsstilfragebogen für Erwachsene. Göttingen: Hogrefe Verlag, 2005.

22. Samwel HJ, Evers AW, Crul BJ, Kraaimaat FW. The role of helplessness, fear of pain, and passive pain-coping in chronic pain patients. Clin J Pain 2006;22:245-51.

23. Leposavic I, Leposavic L. Attribution style of patients with depression. Srp Arh Celok Lek 2009;137:529-33 (Abstr).

24. Radat F, Koleck M. Pain and depression: Cognitive and behavioural mediators of a frequent association. Encephale 2011;37:172-9.

25. Drugan RC, Basile AS, Ha JH, Healy D, Ferland RJ. Analysis of the importance of controllable versus uncontrollable stress on subsequent behavioral and physiological functioning. Brain Res Brain Res Protoc 1997;2:69-74.

26. Peterson C, Maier SF, Seligman MEP. Learned helplessness. A theory for the age of personal control. New York, NY: Oxford University Press, 1975.
27. Seligman MEP. Helplessness. On depression, development and death. San Francisco: Freeman and Company, 1995.

28. Müller MJ, Netter P. Relationship of subjective helplessness and pain perception after electric skin stimuli. Stress Med 2000;16:109-15.

29. Cho S, Heiby EM, McCracken LM, Lee SM, Moon DE.

Pain-related anxiety as a mediator of the effects of mindfulness on physical and psychosocial functioning in chronic pain patients in Korea. J Pain 2010;11:789-97.

30. Meredith PJ, Strong J, Feeney JA. The relationship of adult attachment to emotion, catastrophizing, control, threshold and tolerance, in experimentally-induced pain. Pain 2006;120:44-52.

31. Burns JW, Elfant E, Quartana PJ. Suppression of pain-related thoughts and feelings during pain-induction: Sex differences in delayed pain responses. J Behav Med 2010;33:200-8. 


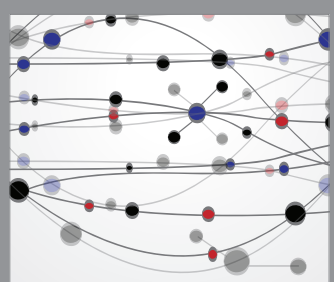

The Scientific World Journal
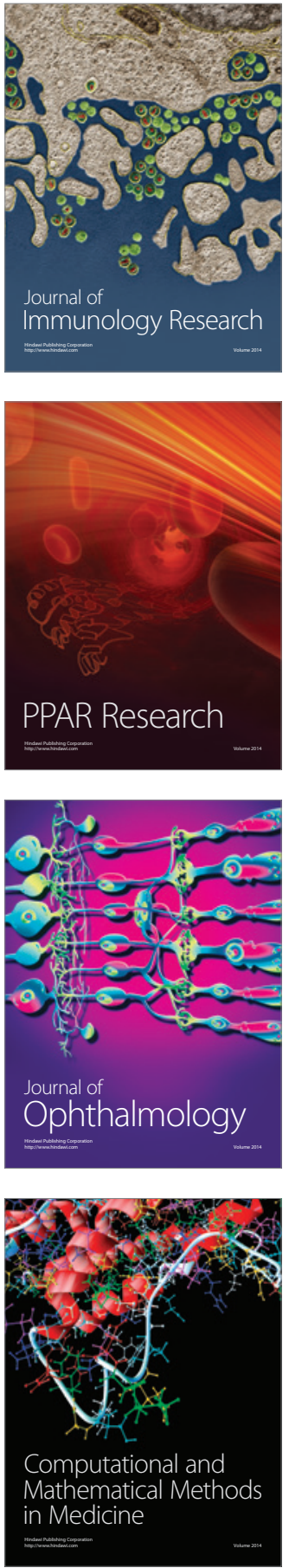

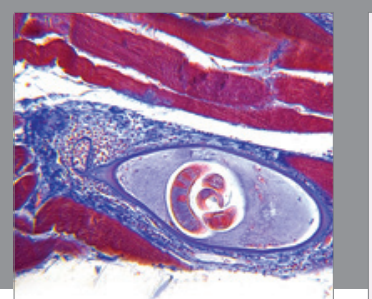

Gastroenterology Research and Practice

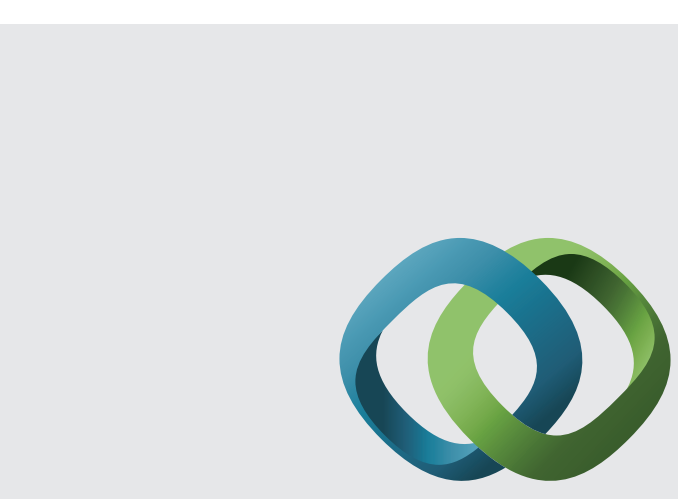

\section{Hindawi}

Submit your manuscripts at

http://www.hindawi.com
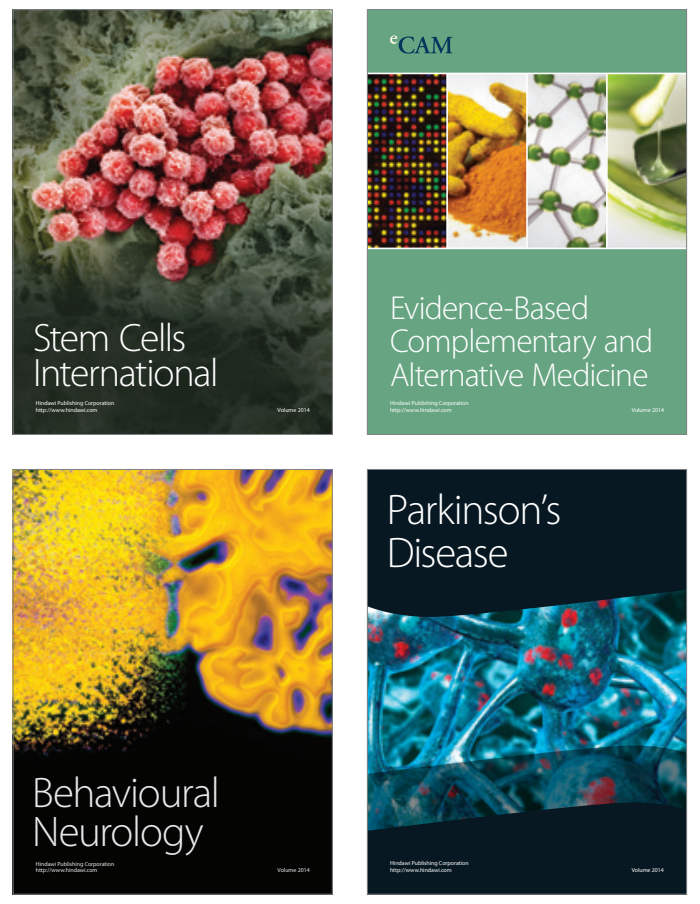
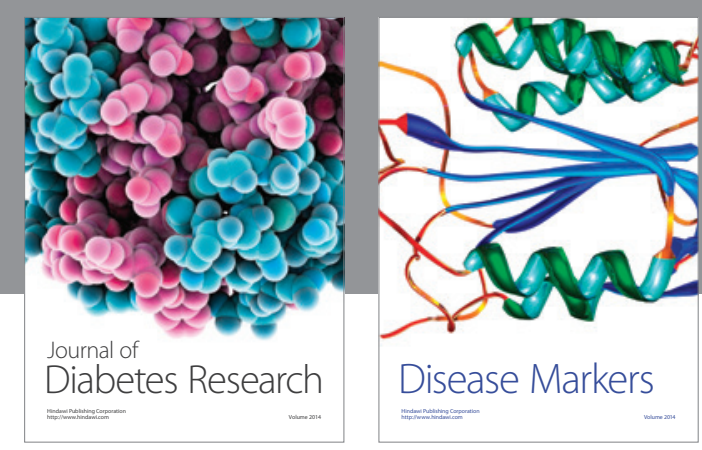

Disease Markers
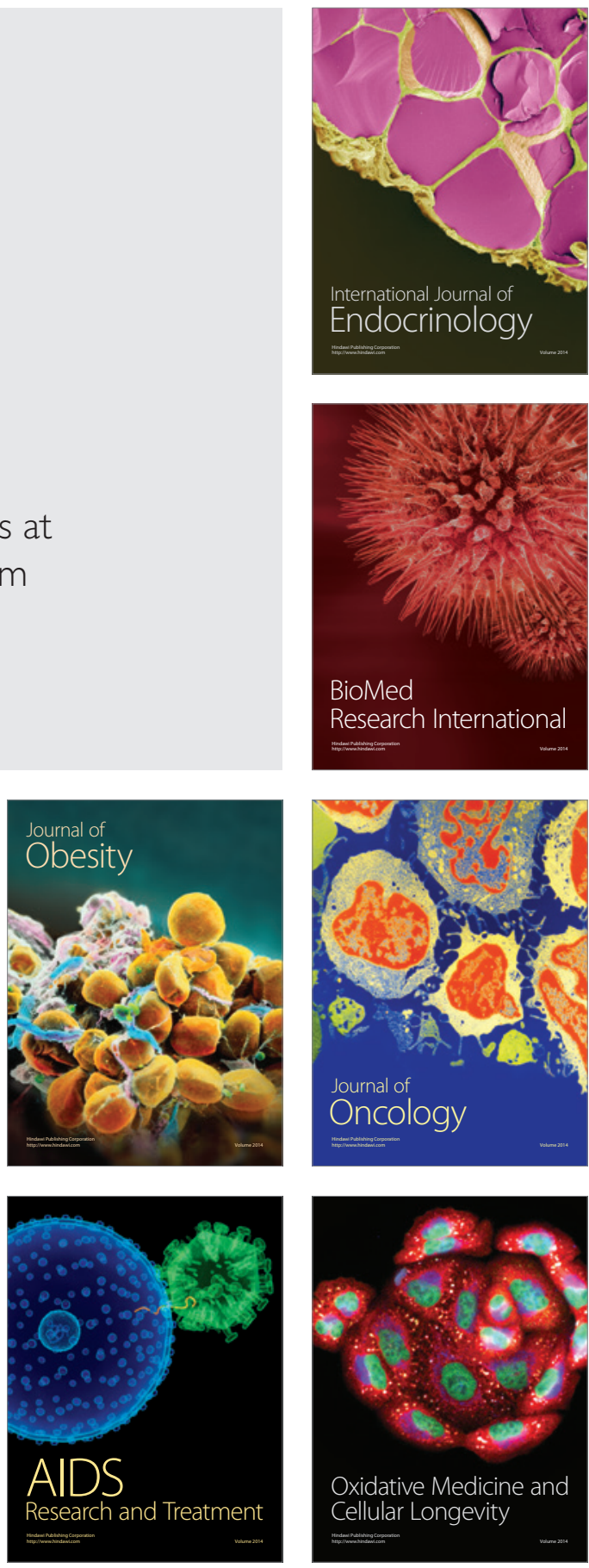